\title{
Total Phenolic Content, Membrane Stabilization and Thrombolytic Activities of Corypha taliera (Arecaceae) Flowers
}

\author{
Akhtaruzzaman Chowdhury ${ }^{1}$, Md. Shafiullah Shajib², Faiza Tahia ${ }^{3}$ \\ Md. Ashraful Alam ${ }^{1}$ and Mohammad A. Rashid ${ }^{3}$ \\ ${ }^{1}$ Department of Chemistry, Rajshahi University of Engineering and Technology, Rajshahi, Bangladesh \\ ${ }^{2}$ Department of Pharmacy, Stamford University Bangladesh, 51 Siddeswari Road, Dhaka-1217, Bangladesh \\ ${ }^{3}$ Department of Pharmaceutical Chemistry, Faculty of Pharmacy, University of Dhaka, Dhaka-1000, Bangladesh
}

(Received: May 21, 2018; Accepted: February 22, 2019; Published (Web): April 01, 2019)

Corypha taliera Roxb. is a monocarpic plant species belonging to the Arecaceae (palm) family. The palm species is considered to be rare and critically endangered in nature. ${ }^{1}$ It flowers once in nearly hundred years and the last flowering plant specimen was found in the campus of University of Dhaka. ${ }^{1-3}$ Collection and characterization of different parts including flowers, fruits and seeds of the plant have been carried out and sustainable strategies towards its protection have been under taken. ${ }^{1,4} \beta$-amyrin, betulinic acid and $\beta$-sitosterol, have been isolated from the $n$-hexane soluble extract of flowers of $C$. taliera. ${ }^{5}$ The unripe fruits of the plant have been reported to contain $\beta$-sitosterol, stigmasterol, lupeol, $\beta$-amyrin and betulinic acid. ${ }^{6}$ GC-MS analysis of the seed pericarp revealed the presence of myristic, oleic, stearic, linoleic, lignoceric and arachidic acids where palmitic acid was predominant. ${ }^{3}$ $\beta$-sitosterol-3-O- $\alpha$-L-rhamnopyranosyl- $(1 \rightarrow 4)-\beta$-D-

xylopyran-osyl-( $1 \rightarrow 4)-\beta$-D-glucopyranosyl- $(1 \rightarrow 4)-\beta$-D-

glucopyranoside, a steroidal glycoside, have been isolated from the seed pericarp. ${ }^{6}$ Recently, the palm species has drawn a significant attention of the scientific community for its potential medicinal values. Fruit extractives of the plant have been reported to exert promising antioxidant as well as cytotoxic activities. The fruit extractives also demonstrated mild to moderate antimicrobial effect against Gram-positive and Gram-negative pathogens. ${ }^{7}$

Correspondence to: Mohammad A. Rashid

Tel: +880-9661900, extn. 8137

E-mail: r.pchem@yahoo.com

Dhaka Univ. J. Pharm. Sci. 18(1): 121-123, 2019 (June)

DOI: https://doi.org/10.3329/dujps.v18i1.41427
It is evident from our rigorous literature review that, biological investigation of C. taliera flower is still lacking. Therefore, as a part of continuation of our investigation on C. taliera $^{2,5,7}$ the methanol extract of C. taliera and its aqueous and organic soluble extractives have been primarily studied for their total phenolic content, membrane stabilization and thrombolytic activities.

Flowers of $C$. taliera have been collected from the plant available in the campus of University of Dhaka, during February-March, 2009. The collected plant flowers were identified by the authentic scientific officer of Bangladesh National Herbarium, where a voucher specimen (accession no: DACB-34180) has been kept for future reference. The collected flowers were subjected to air drying followed by cold extraction using methanol. The concentrated crude methanol extract of flowers of $C$. taliera (MECF) was further fractionated to obtain $n$-hexane (HECF) dichloromethane (DECF) and aqueous (AECF) soluble partitionates by Kupchan method described by Van Wagenen et al. ${ }^{8}$ Quantification of total phenolic content in the extractives of flowers of $C$. taliera was carried out using Folin-Ciocalteu reagent according to the method described by Islam et al. ${ }^{9}$

Membrane stabilizing activity of the extractives (2 $\mathrm{mg} / \mathrm{ml}$ ) of flowers of $C$. taliera was determined by measuring the inhibition of human erythrocytes hemolysis on heat-and hypotonic-solution as described by Shinde et al. ${ }^{10}$ Thrombolytic activity the extractives $(2 \mathrm{mg} / \mathrm{ml})$ was expressed by human blood clot lysis activity as previously described by Miah et al.. ${ }^{11}$ The experiments were conducted under the consent of the Institutional Ethical Review Committee, State University of Bangladesh and 
human volunteers who have donated bloods. The ethical guidelines described in the Declaration of Helsinki 2013 were followed for the experiments. The experiments were carried out thrice for each sample. The data are presented as mean with standard error of mean (SEM) of three replicate experiments.

Table 1. Total phenolic content, membrane stabilizing and thrombolytic activity of different extractives of $C$. taliera flowers.

\begin{tabular}{lcccc}
\hline Test sample/ & TPC in mg & \multicolumn{2}{c}{ Membrane stabilization $(\%)$} & Thrombolytic activity \\
Standard drug & (GAE/gm extract) & Heat-induced & Hypotonic solution-induced & (\% clot lysis) \\
\cline { 3 - 4 } MECF & $193.43 \pm 3.27$ & $56.86 \pm 1.03$ & $45.67 \pm 2.22$ & $31.59 \pm 1.69$ \\
AECF & $158.84 \pm 1.72$ & $52.75 \pm 1.57$ & $24.10 \pm 1.92$ & $27.16 \pm 1.27$ \\
DECF & $143.43 \pm 3.27$ & $44.34 \pm 0.91$ & $17.45 \pm 2.57$ & $23.57 \pm 2.17$ \\
HECF & $93.94 \pm 5.64$ & $18.69 \pm 2.42$ & $7.44 \pm 0.62$ & $18.17 \pm 1.29$ \\
Acetyl salicylic acid & - & $73.50 \pm 1.60$ & $61.95 \pm 2.99$ & - \\
\hline Streptokinase & - & - & - & $63.09 \pm 1.83$
\end{tabular}

Data are presented as mean \pm SEM $(n=3)$. TPC $=$ total phenolic content, GAE $=$ gallic acid equivalent. MECF, HECF, DECF, AECF represents methanol, $n$-hexane, dichloromethane, and aqueous soluble extract of flowers of $C$. taliera, respectively.

The results of the present investigation demonstrated that methanol extract and its different organic extractives of C. taliera possess potent membrane stabilizing and thrombolyltic activities as well as substantial amount of phenolics (Table 1). The total phenolic content assay revealed that the crude methanol extract of the plant flowers (MECF) contain noticeable amount of phenolic compounds (193.43 $\pm 3.27 \mathrm{mg} / \mathrm{gm}$ equivalent to gallic acid), compared to its organic soluble partitionates.

The extract of $C$. taliera flowers showed prominent membrane stabilizing activity in human RBC (red blood cell) membrane stabilization assay. The extracts considerably inhibited the lysis of human RBC membrane induced by heat and hypotonic solution, as compared to the positive control acetyl salicylic acid. The MECF revealed highest inhibition of hemolysis of RBC membrane in hypotonic solution and heat-induced conditions by $56.86 \pm$ 1.03 and $45.67 \pm 2.22 \%$ as compared to other extractives. However, standard acetylsalicylic acid showed remarkable inhibition of the hypotonic and heat-induced RBC membrane lysis by $73.50 \pm 1.60$ and $61.95 \pm 2.99 \%$, respectively (Table 1). Human RBC membrane is analogous to lysosomal membrane and inhibition of both hypotonic solution and heat induced hemolysis of RBCs might be considered as a parameter of the plant's antiinflammatory potential. $^{12,13}$ It has been reported that, tannins, phenolic compounds might act as promising membrane stabilizer. ${ }^{14}$ Therefore, phenolics present in $C$. taliera flowers extractives could be partly responsible for the membrane stabilizing activity.

The crude methanol extract of $C$. taliera flowers and its organic soluble materials were investigated to determine their thrombolytic activity by means of RBCs clot lysis activity. The result exhibited that, different extractives of C. taliera flowers showed considerable clot lysis of RBCs, ranging from $18.17 \pm 1.29$ to $31.59 \pm 1.69 \%$. The highest activity was exhibited by the crude methanol extract of the plant flowers (MECF) compared to its other partitionates. However, the effect was more promising for the standard drug, streptokinase $(63.09 \pm 1.83 \%)$, when compared to the plant extractives (Table 1). Blood clot formation may cause clogging of blood vessels, with the help of deposition of fibrin, platelets and tissue factors and results in severe thromboembolic consequences such as stroke, arthritis, and myocardial ischemia. ${ }^{15,16}$ The results suggest that the crude extract of the plant flowers might act prominently against blood clot formation as wall thromboembolic disorders.

Finally, it can be deduced from the result of present investigation that the crude methanol extract of flowers of C. tailera and its aqueous and organic soluble partitonates possesses significant phenolic content. The methanol extract has considerable membrane stabilizing and thrombolytic potentials compared to its aqueous and organic soluble partitonates. The study primarily revealed the potential bioactivities of the plant flowers extracts. However, further chemical and biological studies of the 
flowers extractives are required to investigate the substance(s) responsible for such bioactivities as well as isolation and characterization of the active molecules. Consideration of the outcomes of the present study might worth for the future investigations.

\section{ACKNOWLEDGEMENT}

One of our author (MAR) is grateful to the Ministry of Education, Government of the People's Republic of Bangladesh for a research grant (No. $37.01 .0000 .078 .02 .018 .13-125 / 10 / 2 / 2015)$ to him for the period 2014-15 to 2016-17 to accomplish the work.

\section{REFERENCES}

1. Khondker, M., Hassan, M.A., Alfasane, M.A. and Shsahjadee, U.F. 2010. Flowering and fruiting characteristics and biochemical composition of an endangered palm species (Coryphataliera Roxb.). Bangladesh J. Plant Taxon. 17, 79-86.

2. Khan, M.F., Rashid, R.B., Hossain, M.A. and Rashid, M.A. 2017. Computational study of solvation free energy, dipole moment, polarizability, hyperpolarizability and molecular properties of Betulin, a constituent of Corypha taliera (Roxb.). Dhaka Univ. J. Pharm. Sci. 16, 1-9.

3. Shoeb, M., Nusrat, S.E. and Khondker, M. 2013. Chemical investigation of Corypha taliera Roxb. Bangladesh J. Bot. 42, 51-54.

4. Chowdhury, A., Alam M.A., Shajib, M.S., Al-Mansur, M.A. and Rashid, M.A. 2017. Chemical constituents and protection of biodiversity of Corypha taliera Roxb., a critically endangered plant of Bangladesh. Bangladesh Pharm. J. 20, 213-220.

5. Chowdhury, A., Alam, M.A., Rashid, R.B., Al-Mansur, M.A., Rahman, M.S., Rashid, M.A. 2013. Steroids and triterpenoids from Corypha taliera Roxb: a critically endangered palm species of Bangladesh. Res. J. Med. Plant 7, 125-129.
6. Shoeb, M., Khondker, M., Nahar, N. 2016. A new steroidal glycoside from Corypha taliera Roxb., a globally endangered species. Nat. Prod. Res. 30, 281-285.

7. Chowdhury, A., Alam, A., Rahman, M.S., Hassan, A., Rashid, M.A. 2010. Antioxidant, antimicrobial and cytotoxic activities of Corypha taliera Roxb. Lat. Am. J. Pharm. 29, $1231-1234$

8. VanWagenen, B.C., Larsen, R., Cardellina II, J.H., Randazzo, D., Lidert, Z.C. and Swithenbank, C. 1993. Ulosantoin, a potent insecticide from the sponge Ulosaruetzleri. J. Org. Chem. 58, 335-337.

9. Islam, S., Shajib, M.S. and Ahmed, T. 2016. Antinociceptive effect of methanol extract of Celosia cristata Linn. in mice. BMC Complement. Altern. Med. 16, 400.

10. Shinde, U.A., Phadke, A.S., Nair, A.M., Mungantiwar, A.A., Dikshit, V.J. and Saraf, M.N. 1999. Membrane stabilizing activity - a possible mechanism of action for the antiinflammatory activity of Cedrus deodara wood oil. Fitoterapia 70, 251-257.

11. Miah M.M., Das P., Ibrahim Y., Shajib M. S., and Rashid M.A. 2018. In vitro antioxidant, antimicrobial, membrane stabilization and thrombolytic activities of Dioscorea hispida Dennst. Eur. J. Integr. Med. 19, 121-127.

12. Shinde, U.A., Phadke, A.S., Nair, A.M., Mungantiwar, A.A., Dikshit, V.J. and Saraf, M.N. 1999. Membrane stabilizing activity - a possible mechanism of action for the antiinflammatory activity of Cedrus deodara wood oil. Fitoterapia 70, 251-257.

13. Sikder, M.A.A., Millat, M.S., Sultana, A., Kaisar, M.A. and Rashid, M.A. 2012. In vitro membrane stabilizing activity, total phenolic content, cytotoxic, thrombolytic and antimicrobial activities of Calliandra surinamensis (Wall.). J. Pharmacogn. Phytochem. 1, 40-44.

14. Fabricant, D.S. and Farnsworth, N.R. 2001. The value of plants used in traditional medicine for drug discovery. Environ. Health Perspect. 109, 69-75

15. Bick, R.L. and Kaplan, H. 1998. Syndromes of thrombosis and hypercoagulability: congenital and acquired causes of thrombosis. Med. Clin. North. Am. 82, 409-458.

16. Furie, B. and Furie, B.C., 2008. Mechanisms of thrombus formation. N. Engl. J. Med. 359, 938-949. 